\title{
Evolution of Characteristics of the Zone of Rock Loosening with Cross-Sectional Area
}

\author{
Jun Liu (1), Liwei Chen, Ning Li, and Xiangjun Chen \\ School of Safety Science and Engineering, Henan Polytechnic University, Jiaozuo, 454000 Henan, China \\ Correspondence should be addressed to Jun Liu; liujun5027@163.com
}

Received 20 April 2020; Accepted 13 August 2021; Published 29 August 2021

Academic Editor: Hualei Zhang

Copyright ( 2021 Jun Liu et al. This is an open access article distributed under the Creative Commons Attribution License, which permits unrestricted use, distribution, and reproduction in any medium, provided the original work is properly cited.

\begin{abstract}
Because of the large deformation of surrounding rock mass and the different deformation characteristics of roadways with different cross-sectional areas, it is difficult to determine the means of support of roadways and the hole-sealing depth of extraction boreholes, which will cause serious roadway deformation and reduce the gas drainage rate. In order to solve these problems, this paper studies the evolution law of the zone of rock loosening around the roadway at four different cross-sectional areas $\left(15 \mathrm{~m}^{2}, 20 \mathrm{~m}^{2}, 25 \mathrm{~m}^{2}, 30 \mathrm{~m}^{2}\right)$ by means of the acoustic field tests and numerical simulation. The results revealed three key points: first, the zone of rock loosening around the roadway is symmetrically distributed around the center of the roadway, and its shape is approximately that of a "butterfly." Second, field tests results indicate that the rock loose zone of 1302 North floor mining roadway is in the range of $2.3-2.4 \mathrm{~m}$ on the side of the roadway and is $2.7-$ $2.9 \mathrm{~m}$ on the central auxiliary transportation roadway. The simulation results show that the rock loose zone of 1302 North floor mining roadway is $2.5 \mathrm{~m}$ on the side of the roadway and is $3.0 \mathrm{~m}$ on the central auxiliary transportation roadway. The simulation results under four different section areas matched the field test results well, and the range of the surrounding rock loosening zone increases with the increased cross-sectional area. Third, the loose zone at the top corner and side of the roadway has a linear relationship with the cross-sectional area, and the loose zone at the bottom corner of the roadway does not change significantly with the cross-sectional area. These results have significance for determining the cross-sectional area of mine roadways in the same geological conditions, the sealing depth of the borehole, and the surrounding rock support.
\end{abstract}

\section{Introduction}

During the process of roadway excavation, the original stress equilibrium state of surrounding coal and rock mass is destroyed, and the surrounding rock mass changes from the original state of three-dimensional stress equilibrium to a two-dimensional stress state, resulting in an increase of tangential stress and a decrease of radial stress [1]. The stress of surrounding rock will be redistributed in a short time, and the stress will be concentrated around the roadway. If the concentrated stress value does not exceed the rock's strength, the surrounding rock will be in a state of elastic self-stability. In contrast, if the value of concentrated stress exceeds the strength of rock after falling, the surrounding rock will break, and this will gradually extend from the periphery to deeper layers, until reaching another new state of three-dimensional stress equilibrium [2]. During this process, a range of damage and looseness is initiated in the surrounding rock this is called the roadway-surrounding rock loosening zone.

Because of the requirements of the detailed rules for prevention and control of coal and gas outbursts, regional-outburst prevention measures must be taken in outburst mines. Predrainage of coal seam gas is the most commonly used regional method of prevention of outburst in China. The sealing length of gas drainage boreholes is an important parameter determining the effect of gas drainage. The determination of the reasonable sealing depth and distance of gas drainage boreholes is closely related to the size of the zone of rock loosening. At the same time, the type of roadway support and the length of anchor cable/anchor bolts are directly related to the size of the zone of rock loosening. Therefore, it is important to 
determine the distribution law of the zone of rock loosening for improving the efficiency of gas drainage, maintaining the stability of the surrounding rock, preventing accidental coal and gas outbursts and deformation of the surrounding rock, and ensuring the safe production of the coal mine [3].

Considerable research has been carried out on the distribution of the loose zone of the surrounding rock. Xie et al. simulated the distribution of fractures of the mining rock mass, using model tests on similar materials, thereby deriving the evolution law of the fracture network and provided insights to the design of deep roadway supports [4-6]. Wen et al. studied the influence of weak intercalation on the progressive failure mode of rock surrounding tunnels by using similar material in a simulation experiment and found that weak intercalation increased the range of the failure zone, and this made the stress distribution uneven, which affected the stability of rock surrounding the tunnel $[7,8]$. Moreover, the location, dip angle, thickness of the weak interlayer, and the distance between the interlayer and the tunnel were important factors affecting the stability of the tunnel. By applying elastic mechanics, Chen et al. derived the distribution of the displacement and stress fields after tunnel excavation and derived the calculation formula for the radius of the zone of rock loosening. Furthermore, they analyzed the influence of the earth stress, support stress, and the firmness coefficient of the surrounding rock on the distribution of the zone of rock loosening [9-12]. Li revised the theory of a balanced arch, put forward an analysis method to predict the loose pressure of surrounding rock of deep buried double tunnels, compared the results with field monitoring data, and achieved good consistency [13]. He et al. studied rock stability around a site tunnel by using the geological radar method, borehole image method, and infrared imaging technology. They obtained the propagation direction of the stress wave caused by excavation and the range of the zone of rock loosening, so that the site support scheme had the data to support the design of a reliable ground structure [14-18]. Shen carried out a detailed numerical simulation of the stability and deformation of a roadway under different roof support schemes through simulation, taking a deep mine as the experimental background, and proposed a new roadway support scheme, which significantly improved the stability of the surrounding rock of the roadway [19-21]. Yu et al. studied the permeability and deformation behaviors of soft rock and sandstones through the experimental method and numerical calculation $[22,23]$. Based on the M-C criterion, Wang et al. [24] deduced the analytical solutions of stress and surrounding rock in the broken zone and plastic zone of the circular roadway. Zhao et al. [25] studied the distribution of the deviatoric stress field and strain energy density of the surrounding rock under triaxial stress, and the results showed that for the $\sigma_{z}$ dominant stress field, it is necessary to pay attention to the " $\mathrm{X}$ "-shaped expansion of the surrounding rock plastic zone. These previous studies mainly focused on one kind of roadway and determined the range of the zone of rock loosening in their theoretical analysis, utilizing similar experiments, numerical simulations, and field measurements. In contrast, research on the evolution law of the zone of rock loosening under different cross-sectional areas is less common.
The acoustic field tests were conducted on the central auxiliary transportation roadway and the North bottom extraction roadway from the Yuxi coal mine to study the evolution law of the zone of rock loosening around the roadway under different cross-sectional areas. In addition, the rock roadway with different section areas was used to perform numerical simulations, and the relationship between different positions and cross-sectional areas around the roadway is analyzed. Our results have significance for the determination of the cross-sectional area of a roadway, the sealing of extraction boreholes, and the support of surrounding rock.

\section{Theoretical Analysis of Surrounding Rock Zone of Rock Loosening}

The rock around the roadway is in one of three states: a zone of rock loosening, a plastic zone, and an elastic zone (Figure 1; in the figure, $\mathrm{b}$ represents the zone of rock loosening, $\mathrm{p}$ represents plastic zone and e represents the elastic zone). The roadway cross-sectional area is $r_{0}$, the roadway support stress is $P z$, and the original surrounding rock stress of the roadway at infinity is $P_{0}$. The radii of the surrounding zone of rock loosening and plastic zone around the roadway are $\left(R_{b}-r_{0}\right)$ and $\left(R_{p}-R_{b}\right)$, respectively. In order to facilitate the calculation, the following assumptions were made: (1) the surrounding rock around the roadway is uniform and isotropic; (2) the roadway is in the hydrostatic stress field, and the lateral pressure coefficient is 1; and (3) the roadway is infinitely long, which can be solved as a plane strain problem.

In the rock surrounding a roadway, the deformation of the elastic zone meets Hooke's law, and the stress of the rock mass meets the following formulae [26].

$$
\begin{gathered}
\sigma_{r}^{e}=p_{0}-\left(p_{0}-\sigma_{r e}\right)\left(\frac{R_{p}}{r}\right)^{2}, \\
\sigma_{\theta}^{e}=p_{0}+\left(p_{0}-\sigma_{r e}\right)\left(\frac{R_{p}}{r}\right)^{2},
\end{gathered}
$$

where $p_{0}$ is the original surrounding rock stress of the roadway, $R_{p}$ is the radius of the plastic zone, and $\sigma_{r e}$ is the radial stress at the junction of the elastic zone and the plastic zone. According to the Mohr Coulomb yield criterion, it meets the following formula:

$$
\sigma_{r e}=\left(2 p_{0}-\sigma_{c}\right) /(\zeta+1),
$$

where $\zeta$ is the slope of the strength line, which can be calculated according to $(1-\sin \varphi) /(1+\sin \varphi) ; \varphi$ is the internal friction angle of the rock mass; and $\sigma_{c}$ is the uniaxial compressive strength. 


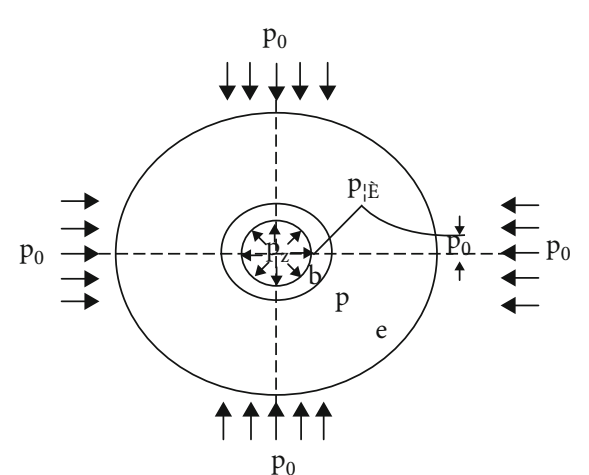

FIGURE 1: Schematic diagram of stress state of rock surrounding a roadway.

Combined with the physical and geometric equations [27], the radial displacement of the elastic region is given by

$$
u_{e}=\varepsilon_{r}^{e} r=\frac{(1+\mu)\left(\sigma_{r e}-p_{0}\right)}{E r} R_{p}^{2}=A \frac{R_{p}^{2}}{E},
$$

where $e$ is the elastic modulus.

For ease of calculation, $A$ is defined as $A=(1+\mu)\left(\sigma_{r e}-p_{0}\right) / r$. At the junction of the elastic and plastic zones, the geometric equation can be obtained as follows:

$$
\sigma_{\theta}^{e}=-\sigma_{r}^{e}=A
$$

In the rock surrounding the tunnel, the total strain in the plastic zone is given by

$$
\begin{aligned}
& \varepsilon_{r}=\left(\varepsilon_{r}^{e}\right)_{r=R_{p}}+\varepsilon_{r}^{p}, \\
& \varepsilon_{\theta}=\left(\varepsilon_{\theta}^{e}\right)_{r=R_{p}}+\varepsilon_{\theta}^{p} .
\end{aligned}
$$

For the rock surrounding the roadway, the volume deformation of the rock mass in the elastic area is small and can therefore be ignored. In the plastic softening and failure areas, there are expansion characteristics. Considering the flow rule of the volume expansion of the rock mass [28], in the plastic area

$$
\Delta \varepsilon_{r}^{p}+\eta_{1} \Delta \varepsilon_{\theta}^{p}=0
$$

where $\Delta \varepsilon_{r}^{p}$ and $\Delta \varepsilon_{\theta}^{p}$ are the radial and tangential strain increments in the plastic zone, respectively; $\eta_{1}$ is the coefficients related to the expansion of rock mass in the plastic zone, $\eta_{1} \geq 1$, and meets $\eta_{1}=\zeta=(1-\sin \varphi) /(1+\sin \varphi)$.

According to the geometric equation, we get

$$
\frac{d u}{d r}+\eta_{1} \frac{u}{r}=A\left(\eta_{1}-1\right)
$$

Combined with the radial displacement $\left.u^{e}\right|_{r=R_{p}}=A R_{p}$ at the junction of elastic and plastic zones, the flow rule in plas- tic zone, and the Mohr Coulomb yield rule, we get

$$
\sigma_{\theta}^{p}=\zeta \sigma_{r}^{p}+\sigma_{c}-\frac{2 A M_{c}}{\eta_{1}+1}\left[\left(\frac{R_{p}}{r}\right)^{1+\eta_{1}}-1\right] .
$$

According to the static equilibrium equation and boundary condition $\left(\sigma_{r}^{e}\right)_{r=R_{p}}=\left(\sigma_{r}^{p}\right)_{r=R_{p}}$, the stress expression of the plastic zone can be obtained as follows:

$$
\begin{gathered}
\sigma_{r}^{p}=\frac{2}{\zeta+1}\left[p_{0}+\frac{\sigma_{c}}{\zeta-1}+\frac{(\zeta+1) A M_{c}}{(\zeta-1)\left(\zeta+\eta_{1}\right)}\right]\left(\frac{r}{R_{p}}\right)^{\zeta-1} \\
+\frac{2 A M_{c}}{1+\eta_{1}}\left[\frac{1}{\zeta+\eta_{1}}\left(\frac{R_{p}}{r}\right)^{1+\eta_{1}}-\frac{1}{1+\eta_{1}}\right]-\frac{\sigma_{c}}{\zeta-1}, \\
\sigma_{\theta}^{p}=\zeta \sigma_{r}^{p}+\sigma_{c}-\frac{2 A M_{c}}{\eta_{1}+1}\left[\left(\frac{R_{p}}{r}\right)^{1+\eta_{1}}-1\right] .
\end{gathered}
$$

In rock surrounding the roadway, the total strain in the zone of rock loosening satisfies the following formula:

$$
\begin{gathered}
\varepsilon_{r}=\left(\varepsilon_{r}^{p}\right)_{r=R_{b}}+\varepsilon_{r}^{b}, \\
\varepsilon_{\theta}=\left(\varepsilon_{\theta}^{p}\right)_{r=R_{p}}+\varepsilon_{\theta}^{b} .
\end{gathered}
$$

Considering the flow rule of volume expansion of rock mass, the zone of rock loosening is as follows:

$$
\Delta \varepsilon_{r}^{p}+\eta_{2} \Delta \varepsilon_{\theta}^{p}=0
$$

where $\Delta \varepsilon_{r}^{p}$ and $\Delta \varepsilon_{\theta}^{p}$ are the radial and tangential strain increments in the zone of rock loosening, respectively; $\eta_{2}$ is the coefficient related to the expansion of rock mass in the zone of rock loosening, $\eta_{1} \geq 1$, generally taken as $1.3-1.5$.

According to the geometric equation, we get

$$
\left[\left(\varepsilon_{r}^{p}\right)_{r=R_{b}}+\varepsilon_{r}^{b}\right]+\eta_{2}\left(\left(\varepsilon_{\theta}^{p}\right)_{r=R_{p}}+\varepsilon_{\theta}^{b}\right)=0 .
$$

Combined with the Radial displacement $\left.u^{e}\right|_{r=R_{b}}=A R_{b}\{$ $\left.1+\left(2 / 1+\eta_{1}\right)\left[\left(R_{p} / R_{b}\right)^{1+\eta_{1}}-1\right]\right\}$ at the junction of the elastic and plastic zone, the flow rule of the zone of rock loosening [29], the Mohr Coulomb yield rule [30], and the boundary conditions, the stress expression of the zone of rock 
loosening is obtained as follows:

$$
\begin{aligned}
\sigma_{r}^{b}= & \left\{\frac{2}{\zeta+1}\left[p_{0}+\frac{\sigma_{c}}{\zeta-1}+\frac{(\zeta+1) A M_{c}}{(\zeta-1)\left(\zeta+\eta_{1}\right)}\right]\left(\left(\frac{R_{b}}{R_{p}}\right)^{\zeta-1}\right)\right. \\
& \left.-\frac{2 A M_{c}+\left(1+\eta_{1}\right)\left(\sigma_{c}-\sigma_{c}^{e}\right)}{(\zeta-1)\left(\zeta+\eta_{1}\right)}\right\}\left(\left(\frac{r}{R_{p}}\right)^{\zeta-1}\right) \\
& -\frac{\sigma_{c}^{e}}{\zeta-1} \sigma_{\theta}^{b}=\zeta \sigma_{r}^{b}+\sigma_{c}^{e} .
\end{aligned}
$$

In the expression of the zone of rock loosening stress, $r$ is equal to the tunnel radius, and the radial stress of zone of rock loosening is equal to the support stress, $P_{Z}$. The analytical solution for the zone of rock loosening radius is obtained as follows:

$$
\begin{aligned}
R_{b}= & r_{0}\left\{\left\{\frac{2}{\zeta+1}\left[p_{0}+\frac{\sigma_{c}}{\zeta-1}+\frac{(\zeta+1) A M_{c}}{(\zeta-1)\left(\zeta+\eta_{1}\right)}\right]\right.\right. \\
& \cdot\left[\frac{2 A M_{c}}{2 A M_{c}+\left(1+\eta_{1}\right)\left(\sigma_{c}-\sigma_{c}^{e}\right)}\right]^{\frac{\zeta-1}{1+\eta_{1}}} \\
& \left.\left.-\frac{2 A M_{c}+\left(1+\eta_{1}\right)\left(\sigma_{c}-\sigma_{c}^{e}\right)}{(\zeta-1)\left(\zeta+\eta_{1}\right)}\right\} /\left(P z+\frac{\sigma_{c}^{e}}{\zeta-1}\right)\right\}^{\frac{1}{\zeta-1}} .
\end{aligned}
$$

Through the above analysis, it can be concluded that the cross-sectional area of the roadway is closely related to the range of the loosening zone of the rock surrounding the roadway. However, in practice, the cross-sectional shape of the roadway is not a regular circle but is mainly an arched cross-section. Rectangular and trapezoid cross-sections are also widely used. Consequently, this paper analyzes and studies the different sectional areas of an arched crosssection.

\section{Field Measurement of Rock Surrounding the Zone of Rock Loosening}

3.1. Overview of the Mine. Shanxi Lanhua Kechuang Yuxi Coal Mine Co., Ltd. (hereinafter referred to as the "Yuxi coal mine") is located in the south Shanxi Province and is southeast of the Fanzhuang general survey area. The shape of the well field is stepped, being $5.1 \mathrm{~km}$ wide from north to south, $6.78 \mathrm{~km}$ long from east to west, and $29.79 \mathrm{~km}^{2}$ in area. Its geographical location is shown in Figure 2.

The Yuxi coal mine is a coal and gas outburst mine with high outburst risk, a designed production capacity of $2.40 \mathrm{Mt} / \mathrm{a}$, and a service life of 50.7 years. Coal seam 3 is mainly mined within the mine, which is located in the lower part of the Shanxi formation, with a thickness ranging between 5.12 and $7.20 \mathrm{~m}$ and an average thickness of $5.85 \mathrm{~m}$. The roof of the coal seam is mudstone, sandy mudstone, and siltstone; the local part is fine-grained sandstone, and the floor is mudstone. The structure of the coal seam is simple, and it is a stable and minable coal seam in the whole area. Geological exploration and observation of the exposed area have established that the buried depth of coal seam 3 is $505-862 \mathrm{~m}$, the permeability coefficient of the coal seam is $0.1032 \sim 26.58 \mathrm{~m}^{2} / \mathrm{MPa}^{2} \mathrm{~d}$, the maximum original gas content is $25.59 \mathrm{~m}^{3} / \mathrm{t}$, and the maximum original gas pressure is $2.90 \mathrm{MPa}$.

3.2. Field Test Methods. At present, the commonly used testing methods of rock surrounding a zone of rock loosening in China are $[15,31,32]$ (1) acoustic wave analyses, (2) multipoint displacement meter analyses, (3) seismic waves and geological radar analyses, and (4) borehole camera analyses. At present, the acoustic method is generally recognized as a suitable method for measuring the rock surrounding the zone of rock loosening, and a large number of engineering practices have proved the feasibility of this method.

According to elastic theory, and from the wave equation of elastic wave to the static equation of elastic space problem, the relationship between the velocity of ultrasonic P-wave and S-wave and the elastic parameters of the medium can be obtained [33].

$$
\begin{gathered}
V_{p}=\sqrt{\frac{E(1-\mu)}{\rho(1-\mu)(1-2 \mu)}}, \\
V_{s}=\sqrt{\frac{E}{2 \rho(1+\mu)}},
\end{gathered}
$$

where $V_{p}$ is the longitudinal wave velocity of coal $(\mathrm{m} / \mathrm{s})$, $V_{s}$ is the shear wave velocity of coal $(\mathrm{m} / \mathrm{s}), E$ is the elastic modulus of coal (MPa), $\mu$ is the Poisson's ratio of coal, and $\rho$ is the density of coal $\left(\mathrm{kg} / \mathrm{m}^{3}\right)$.

From the above formula, the propagation speed of an ultrasonic wave in the coal body is related to the elastic modulus, Poisson's ratio, and density of the coal body, while the elastic modulus, Poisson's ratio, and density of the coal body are directly related to its compressive strength and compactness. Therefore, the wave speed of the coal body can indirectly reflect the condition of cracking in the coal body, and the change rule of the acoustic time and wave speed at different depths of the roadway can determine the size of the zone of rock loosening around the roadway [34]. Meanwhile, the ground stress reaches the breaking strength of the rock layer, where the roadway is located; therefore, the loose zone starts to develop gradually on the side of the roadway. When the sound wave propagates in rock or the coal seam, its speed will decrease due to the development of fractures, the decrease of density, and the increase of acoustic impedance. In contrast, if the integrity of rock mass is good, the force (stress) is large and density is large, then the propagation speed is also large. Therefore, for a rock mass of the same class, a high measured acoustic wave velocity is indicative of a good integrity of the rock mass and conversely, a low wave velocity indicates that there are cracks in the rock and the rock mass is damaged. The wave velocity of rock mass at different depths from the surface of the surrounding rock is measured by acoustic testing instruments. The depth 


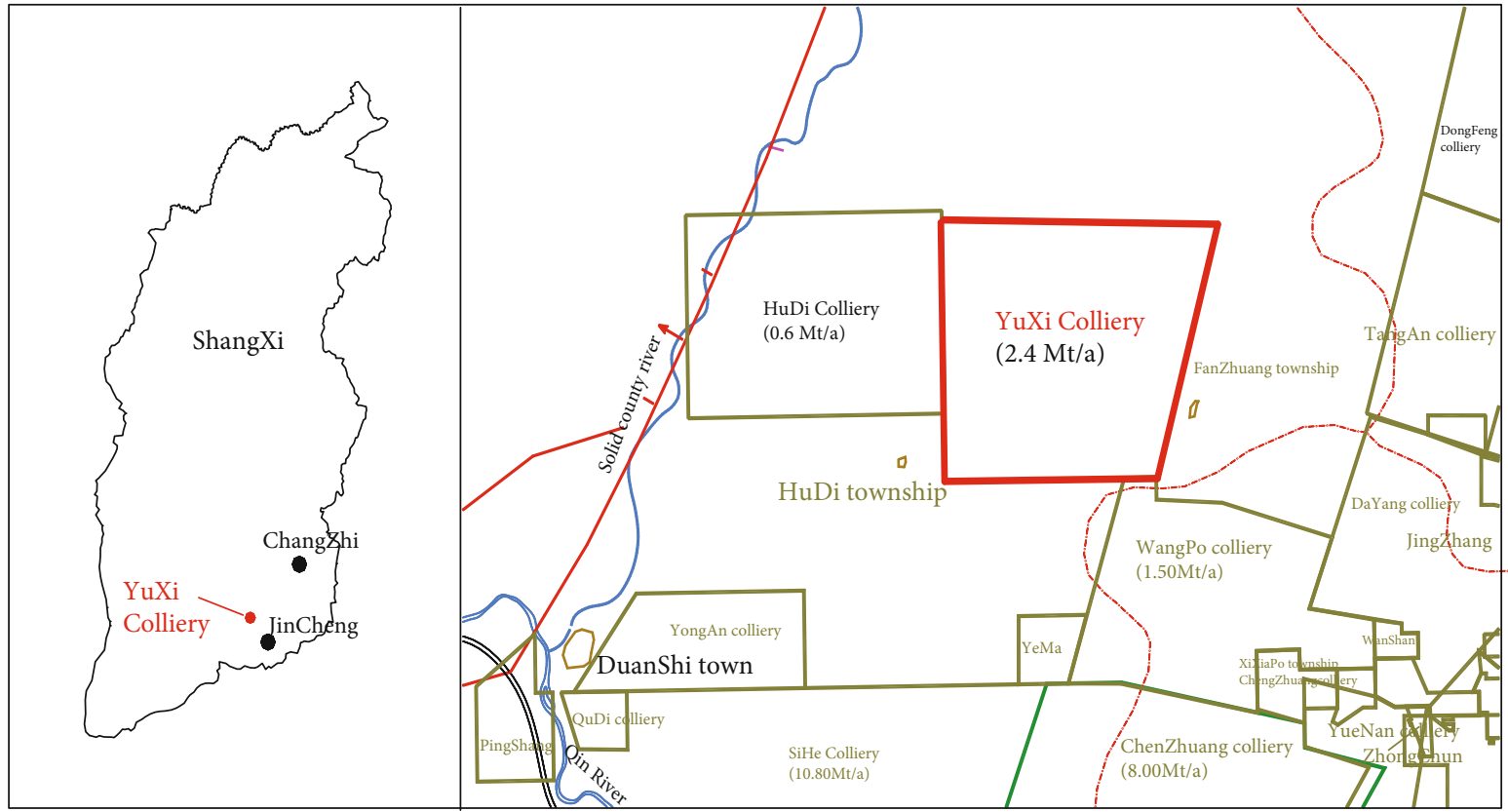

Figure 2: Geographical location of the Yuxi coal mine.

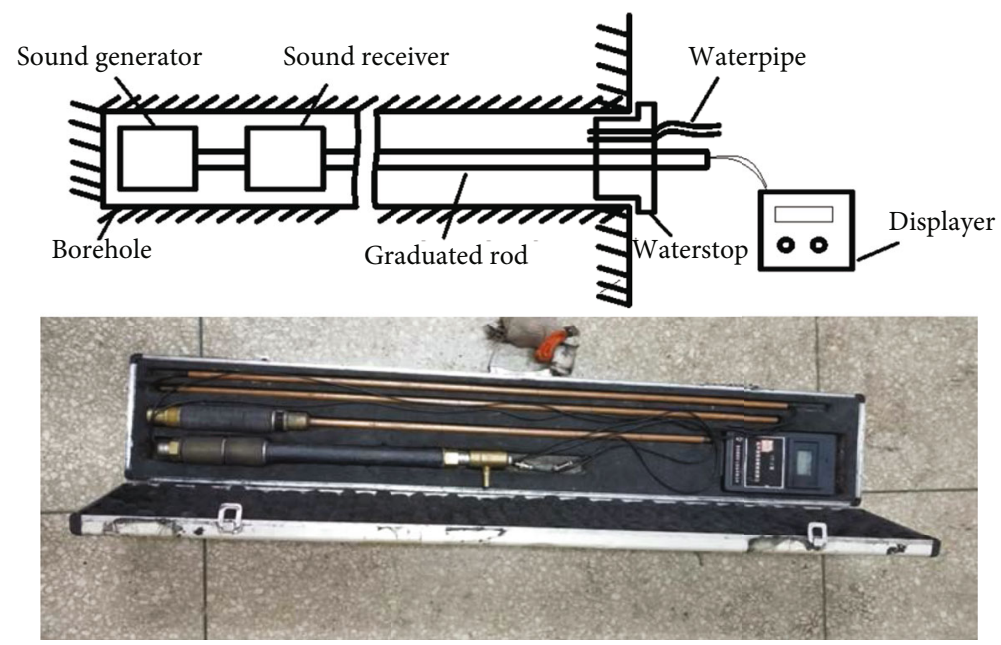

FIGURE 3: Schematic diagram of the single hole test method and CT-2 surrounding rock fracture detector.

and wave velocity curve are then constructed and the thickness of rock surrounding the zone of rock loosening of the roadway is inferred, using relevant geological data [35]. The application of ultrasonic testing to the zone of rock loosening can be divided into the single-hole test method and the double-hole test method. Because of the heavy workload of drilling and the high degree of damage to the surrounding rock, it is difficult for the sounding and receiving probes to move synchronously in the double-hole test. However, the single-hole test method is relatively easy to perform and can yield a large number of test values relatively easily, as a function of the depth of surrounding rock. Consequently, the single-hole test method was selected in the current field tests. Schematic diagrams of a single-hole test and CT-2 surrounding rock fracture detector are shown in Figure 3.
The measurement steps of the zone of rock loosening by the acoustic method are as follows:

(1) Drilling was undertaken at the field test site perpendicular to the side of the roadway, to a drilling depth of $5 \mathrm{~m}$. Subsequent to the drilling, the hole was cleared of debris and the hole was cleaned with clear water until the discharge water was clear of rock slag

(2) The battery was installed in the instrument, the display and circuit of the instrument were checked and the push-pull measuring rod and transceiver were connected. The receiving and transmitting probes were installed at the bottom of the drilling hole through the measuring rod. Additional accessories were inserted into the appropriate position in the 


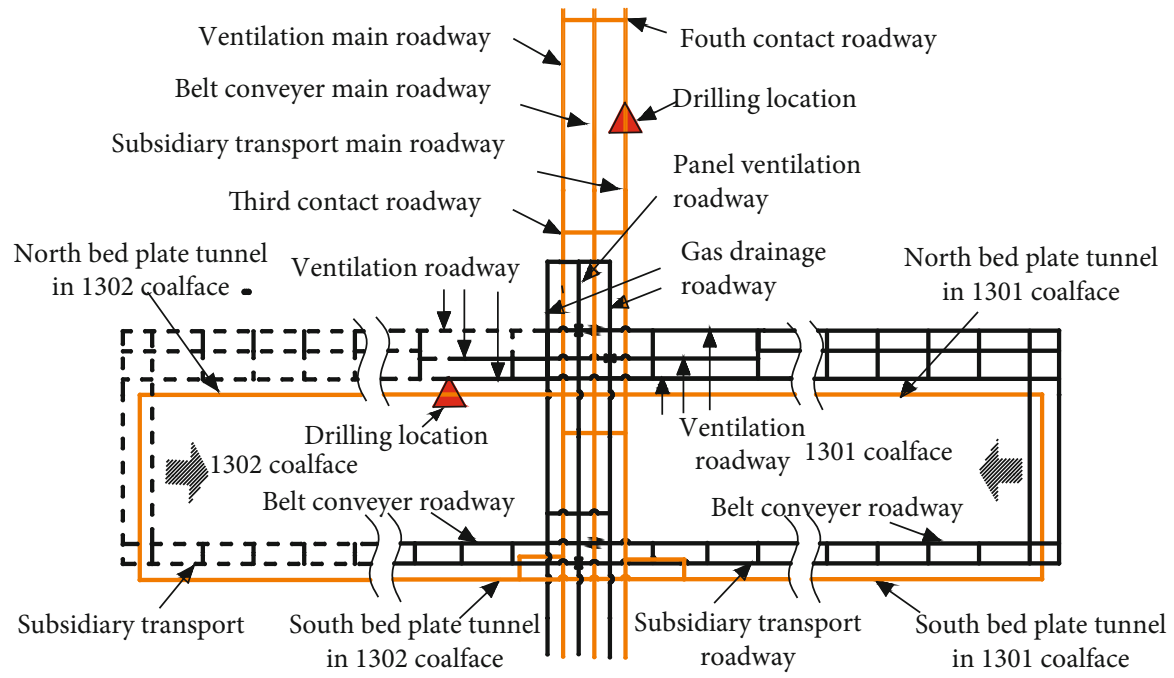

FIgURE 4: Drilling site.

hole and a water stop plug was used to block the drilling hole, followed by injection of the coupling agent (water) to the end of the measuring rod. There was a continuous water outflow

(3) The instrument was initiated to measure the wave velocity of the surrounding rock at different depths using the copper metal measuring rod; four groups of data at each depth were recorded. Data at depth increments of $0.1 \mathrm{~m}$ were recorded until the test was completed

(4) The average of the four groups of data measured at each depth was calculated. Taking the wave velocity as the ordinate and the distance from the roadway side as the abscissa, the relationship between wave velocity and distance from the roadway side was plotted

3.3. Site Measurement Location. The central auxiliary transportation roadway and the North bottom extraction roadway 1302 in the Yuxi coal mine were selected as the test sites for the analyses of roadway zones of rock loosening (Figures 4-6).

The central auxiliary transportation roadway is located in the rock stratum under the floor of coal seam 3 . The roadway cross-section is a straight wall semicircular arch, $5.4 \mathrm{~m}$ wide, $4.3 \mathrm{~m}$ high, and the roadway excavation crosssectional is $20.1 \mathrm{~m}^{2}$. The surrounding rock is mainly grayish black mudstone. The core is a long or short column, prone to scaly and fragmentary cracking, shell fracture, and containing plant fossils, pyrite, and chert nodules; the largest nodule is $5 \mathrm{~cm}$.

The North bottom extraction roadway 1302 and its transport roadway are located in the rock floor stratum of $3 \#$ coal seam. The roadway section is a straight wall semicircular arch section with a width of $4 \mathrm{~m}$, a height of $3.5 \mathrm{~m}$, and a cross-sectional area of $12.6 \mathrm{~m}^{2}$. Gas drainage utilizes an anchor mesh cable support, with a design length of $2157 \mathrm{~m}$. The surrounding rock is mainly black mudstone.

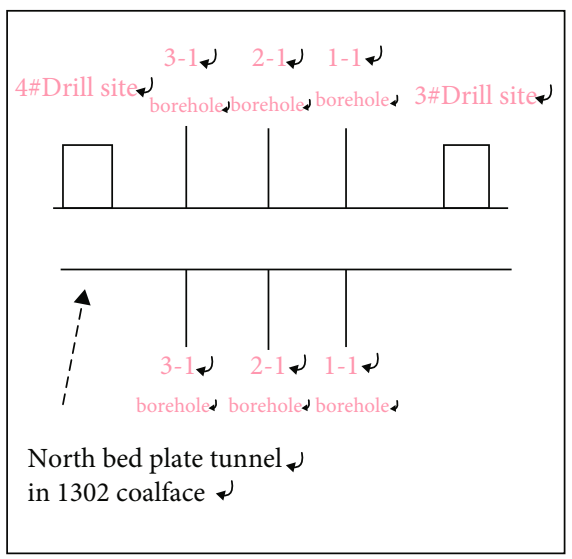

FIgURE 5: Drilling diagram of 1302 North bottom extraction roadway.

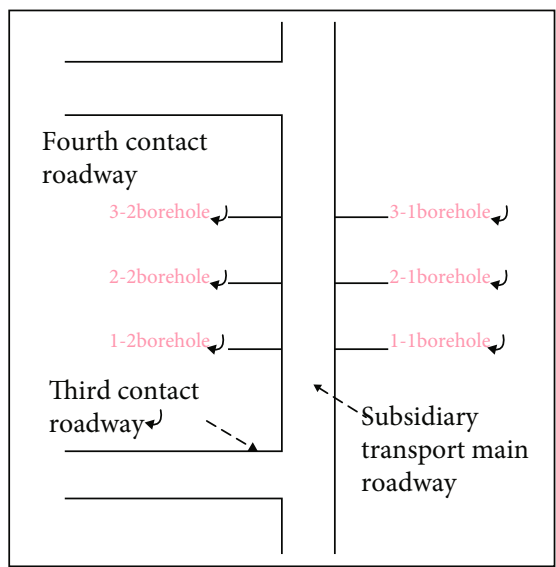

FIgURE 6: Drilling diagram of central auxiliary transportation lane.

The core is a long or short column, scaly or fragmentary, and the shell fracture contains plant fossils and pyrite nodules, with the largest nodule of $5 \mathrm{~cm}$. 

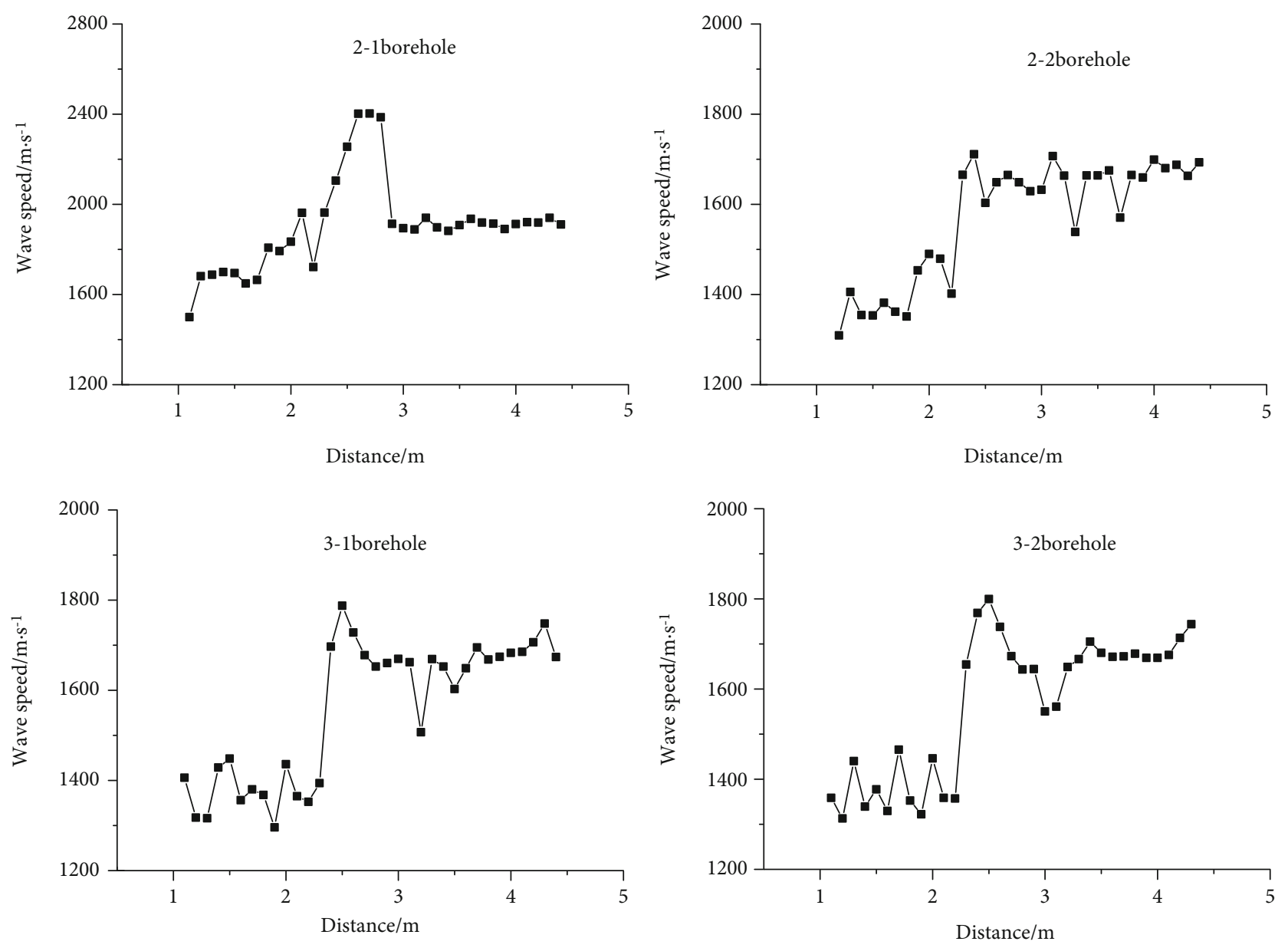

Figure 7: Borehole data of 1302 North bottom extraction roadway.

3.4. Test Results. Due to some problems encountered in the first set of drillings, the first group of data fluctuated greatly and did not show obvious regularity. Consequently, this group of data was not recorded. Figures 7 and 8 show the relationships between wave velocity and distance from the side of the roadway in the bottom extraction roadway 1302 and central auxiliary transportation roadway, respectively.

Analyses of Figures 7 and 8 show that

(1) The wave velocity differed as a function of the distance from the side of the roadway. Take the central auxiliary transportation lane 2-2 drilling as an example, the wave velocity changes slightly within $0.2-2.7 \mathrm{~m}$. When the distance from the side of the roadway attained $2.7 \mathrm{~m}$, wave velocity increased significantly. At this point, with further increase in distance, wave velocity fluctuated within a small range, but velocity was significantly larger than the velocity closer to the side of the roadway

(2) For the 1302 North bottom extraction roadway, boreholes 2-1 and 3-1 were located in the north of the tunnel. In the range of 0.5 to $2.4 \mathrm{~m}$, the average wave velocities were $1740 \mathrm{~m} / \mathrm{s}$ and $1374 \mathrm{~m} / \mathrm{s}$, respectively. After a short increase in distance, the wave velocity increased significantly, reaching the highest value in the measurement range, with average velocities of $2300 \mathrm{~m} / \mathrm{s}$ and $1737 \mathrm{~m} / \mathrm{s}$, respectively, indicating that the rock mass in this range of distances exhibited a high degree of compaction. In the following range, the average wave velocities declined and stabilized at $1910 \mathrm{~m} / \mathrm{s}$ and $1663 \mathrm{~m} / \mathrm{s}$, indicating that the surrounding rock in this range is in the elasticplastic region. Boreholes 2-2 and 3-2 in the south of the tunnel were similar to the boreholes in the north of the tunnel. In the range of $0.5-2.3 \mathrm{~m}$, the average value of velocity is $1740 \mathrm{~m} / \mathrm{s}$, which increased significantly at distances exceeding $2.3 \mathrm{~m}$, and the average velocity was $1660 \mathrm{~m} / \mathrm{s}$. In conclusion, the range of the zone of rock loosening in the North bottom extraction roadway 1302 was $2.3-2.4 \mathrm{~m}$ from the side of the roadway. Similarly, the range of the zone of rock loosening of the central auxiliary transportation roadway was $2.7-2.9 \mathrm{~m}$ from the side of the roadway

(3) Comparing the two sets of field tests, it can be inferred that the range of the surrounding rock 

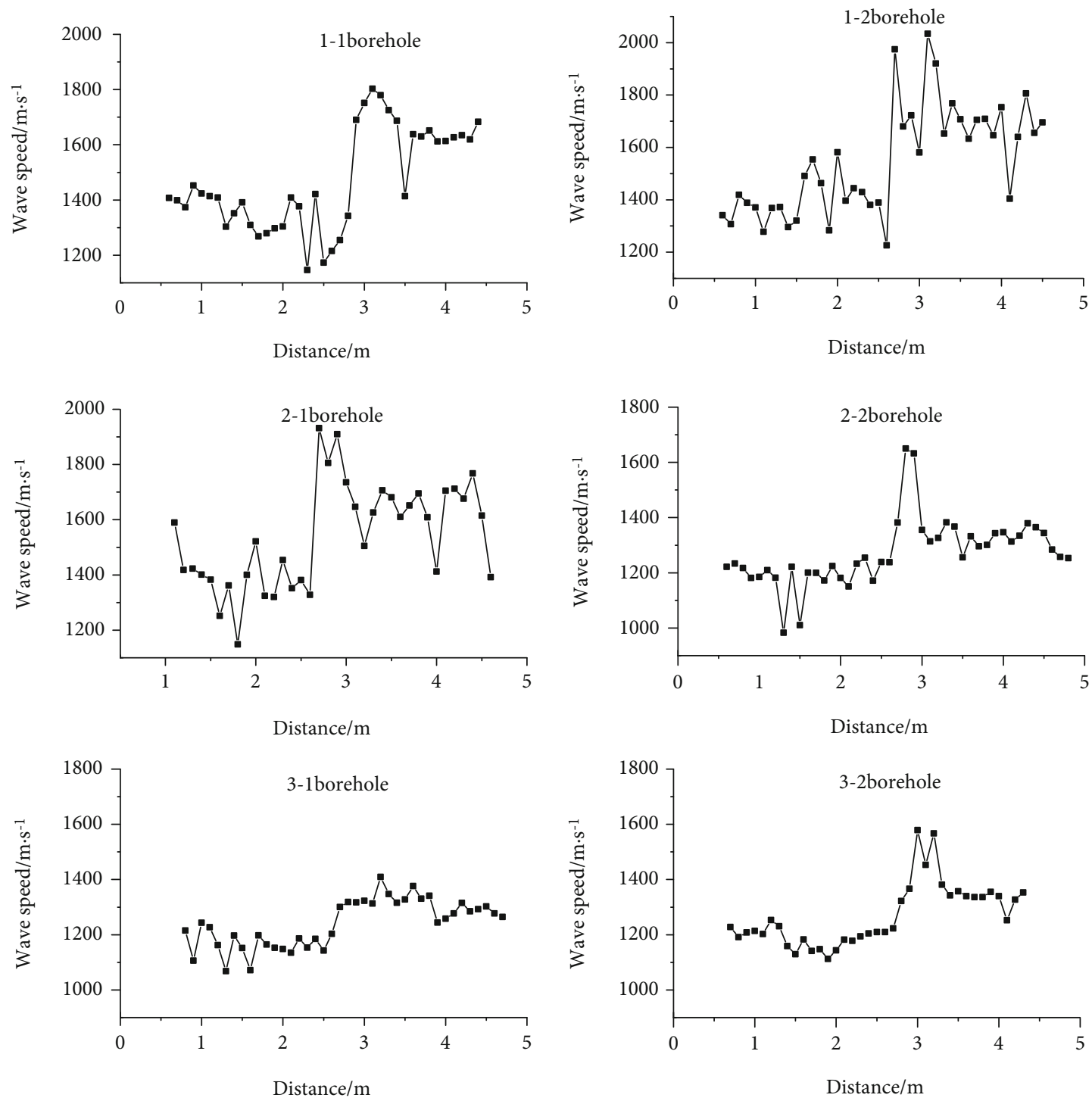

FIgURE 8: Drilling data of central auxiliary transportation lane.

loosening zone increases with an increased crosssectional area

\section{Numerical Simulation of the Evolution of the Zone of Rock Loosening with Different Section Area}

During the process of field testing of the zone of rock loosening, due to the limitation of local experimental conditions, only $12.6 \mathrm{~m}^{2}$ and $20.1 \mathrm{~m}^{2}$ of the zone of rock loosening were obtained from the side of the roadway. According to the change rule of the range of the zone of rock loosening of rock around the roadway with the change of crosssectional area, simulation software is required to verify the rule obtained from the field data. Consequently, in this paper, the field test results were supplemented and verified by numerical simulation.
4.1. Derivation of the Mathematical Model. Because of the influence of geological conditions, the rock mass surrounding the roadway is heterogeneous and discontinuous and exhibits a complex stress field, with bedding and joints. However, a large area was chosen which can be approximately regarded as an isotropic, homogeneous, body. To simplify the problem, the following assumptions were made:

(1) The rock surrounding the roadway is an ideal elasticplastic body, which meets the Mohr Coulomb yield criterion

(2) Each rock stratum has a layered distribution, and the rock mass is an homogeneous isotropic body

(3) Because the dip angle of the rock stratum is small, it is treated as a horizontal rock stratum

(4) The influence of groundwater seepage is not considered 

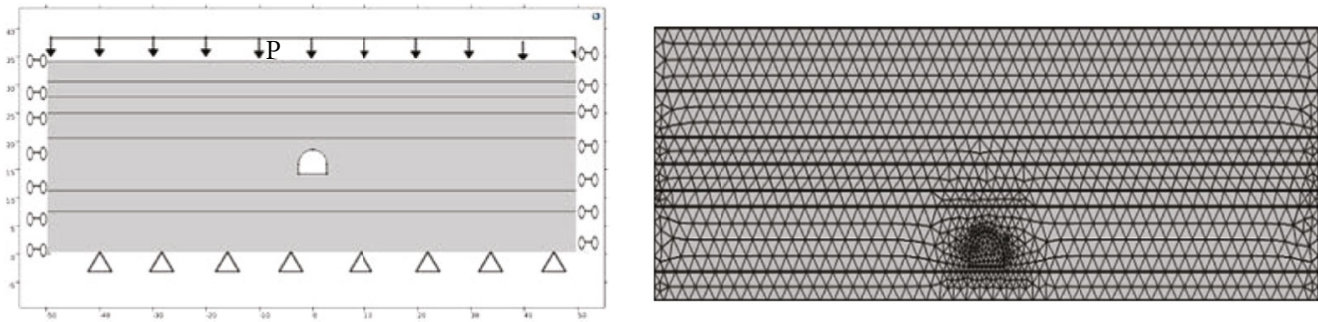

Figure 9: The physical model.

TABle 1: Model parameters.

\begin{tabular}{lccccc}
\hline Rock & Youngs modulus/GPa & Poisson ratio/GPa & Density/kgm ${ }^{-3}$ & Cohesion/MPa & Internal friction angle $\left(^{\circ}\right.$ ) \\
\hline Sandy mudstone & 6.2 & 0.17 & 2676 & 7.80 & 36 \\
Fine sandstone & 7.2 & 0.17 & 2787 & 3.5 & 37 \\
Mudstone & 5.6 & 0.18 & 2700 & 2.60 & 38 \\
Coal & 1.06 & 0.30 & 2460 & 2.35 & 22 \\
Siltstone & 5.65 & 0.22 & 2672 & 2.35 & 32 \\
\hline
\end{tabular}

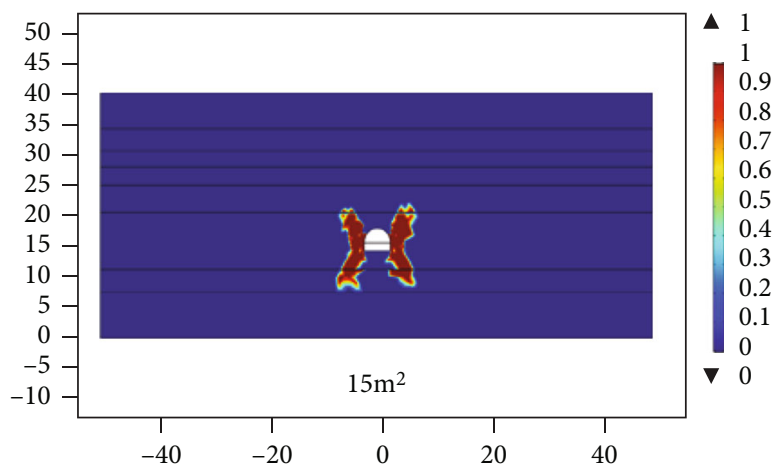

(a) $15 \mathrm{~m}^{2}$

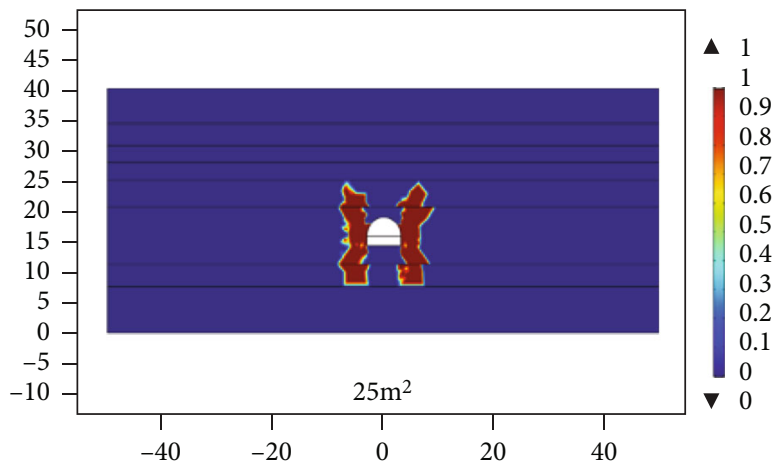

(c) $25 \mathrm{~m}^{2}$

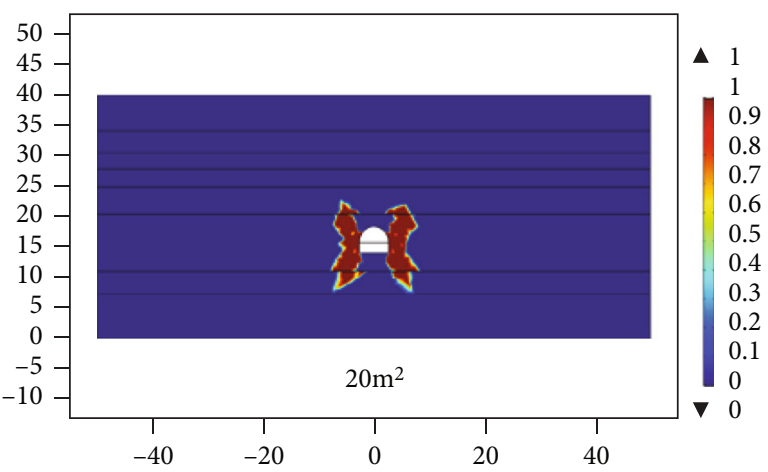

(b) $20 \mathrm{~m}^{2}$

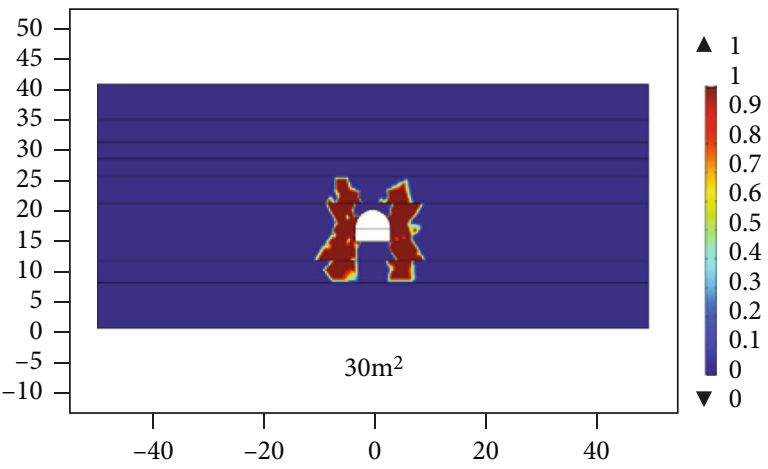

(d) $30 \mathrm{~m}^{2}$

FIGURE 10: Distribution of the one of rock loosening under different cross-sectional areas.

The equilibrium equation of elasticity with solid deformation is

$$
-L \sigma=F,
$$

where $L$ is the differential operator, $\sigma$ is the stress, and $F$ is the volume force.
4.2. Initial and Boundary Conditions. The rock failure criterion is taken as the Mohr Coulomb criterion, and the corresponding in situ stress (the average density of rock is taken as $2500 \mathrm{~kg} / \mathrm{m}^{3}$ ), i.e., $16.5 \mathrm{MPa}$, was loaded on the upper part of the model. A rolling boundary condition was adopted for the left and right sides of the model, and the fixed boundary condition was adopted for the lower part. The initial and boundary conditions of the 


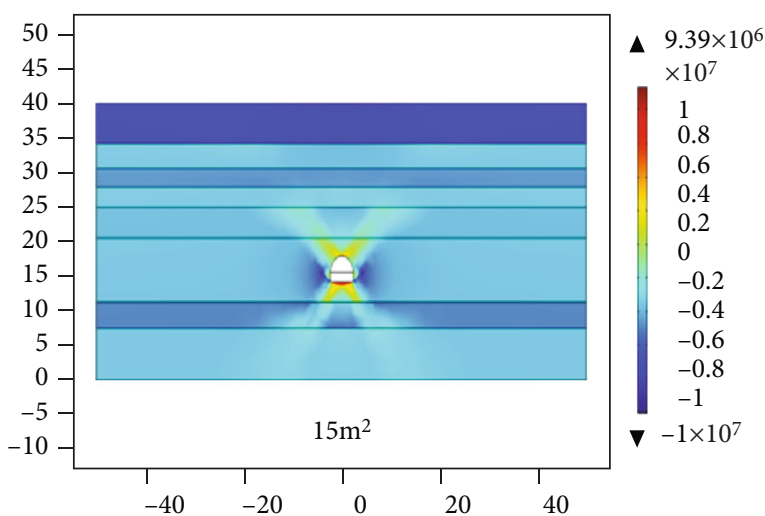

(a) $15 \mathrm{~m}^{2}$

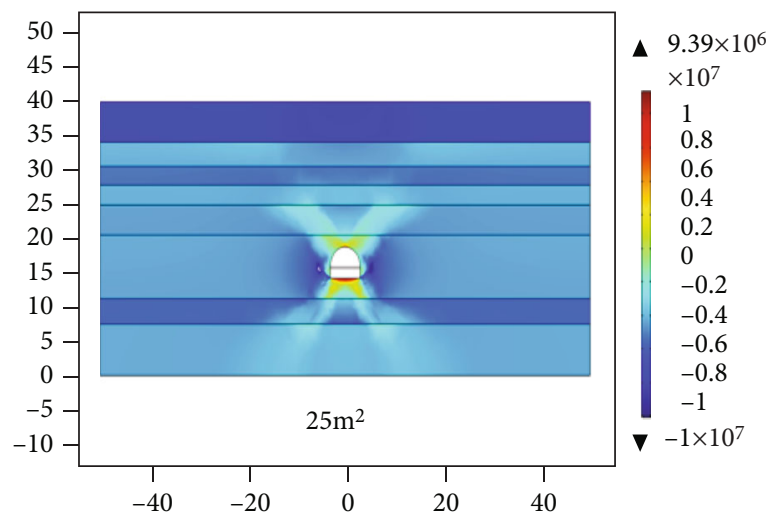

(c) $25 \mathrm{~m}^{2}$

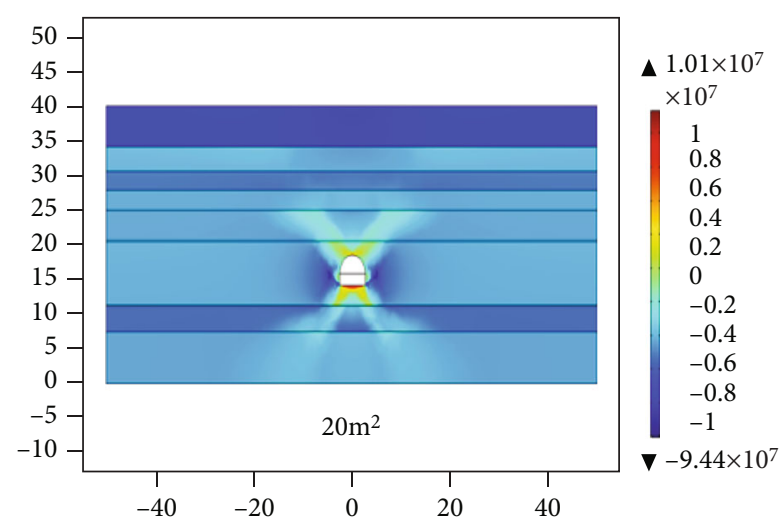

(b) $20 \mathrm{~m}^{2}$

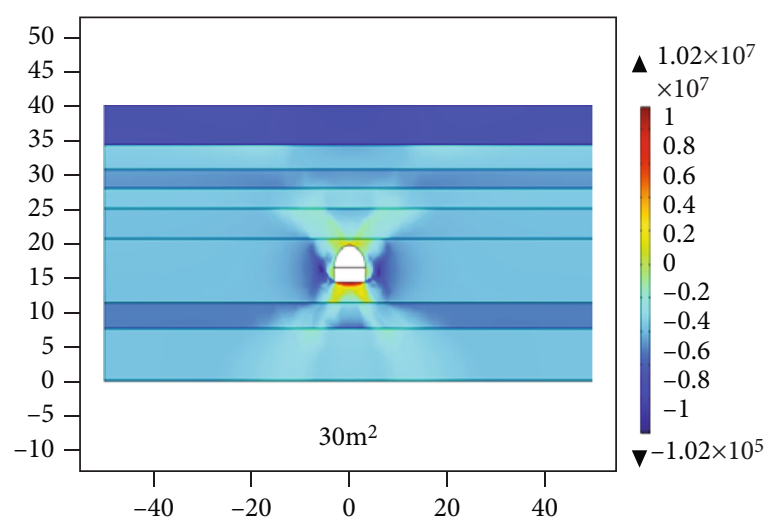

(d) $30 \mathrm{~m}^{2}$

FIGURE 11: Distribution of the stress under different cross-sectional areas.

model are shown in equation (16)

$$
\left\{\begin{array}{l}
\nabla \cdot S+F_{V}=0, \\
F=16.5 M P a, x=35, \\
U=0, y=0, \\
n \cdot u=0, x=-50, x=50 .
\end{array}\right.
$$

4.3. Derivation and Mesh of the Physical Model. We selected the central auxiliary transportation roadway of the Yuxi coal mine as the engineering background of the rock roadway and created a two-dimensional physical model (Figure 9). The model plane was $100 \mathrm{~m} \times 34.31 \mathrm{~m}$, the lithology of rock stratum 1 and 5 are fine-grained sandstone, the lithology of rock stratum 2 and 6 are siltstone, the lithology of rock stratum 3 is sandy mudstone, and the lithology of rock stratum 4 and 7 are mudstone. The model is meshed, as shown in Figure 9.

The cross-sectional area of the middle roadway is $15 \mathrm{~m}^{2}$, $20 \mathrm{~m}^{2}, 25 \mathrm{~m}^{2}$, and $30 \mathrm{~m}^{2}$, respectively. The lithology parameters of each stratum are shown in Table 1.

4.4. Establishment of Physical Model. Through simulation, we can derive a distribution diagram of the rock surrounding the roadway in the zone of rock loosening, with crosssectional areas of $15 \mathrm{~m}^{2}, 20 \mathrm{~m}^{2}, 25 \mathrm{~m}^{2}$, and $30 \mathrm{~m}^{2}$ after the excavation of the roadway (Figure 10). Meanwhile, Figure 11 shows the distribution of the stress under different cross-sectional areas.

Figure 10(a) shows the results of the numerical simulation of cross-section $15 \mathrm{~m}^{2}$, in which the length of the loosened area of the roadside is $2.5 \mathrm{~m}$. Figure 10(b) shows the results of the numerical simulation of cross section $20 \mathrm{~m}^{2}$, in which the length of the loosened area of the roadside is $3 \mathrm{~m}$. Field test results indicate that the rock loose zone of 1302 North floor mining roadway $\left(15 \mathrm{~m}^{2}\right)$ is in the range of $2.3-2.4 \mathrm{~m}$ on the side of the roadway and is $2.7-2.9 \mathrm{~m}$ on the central auxiliary transportation roadway $\left(20 \mathrm{~m}^{2}\right)$. The simulation results under different section areas matched the field tests results well, verifying the reliability of the numerical simulation.

Analysis of Figures 10 and 11 shows

(1) With the excavation of the roadway, the zone of rock loosening around the roadway is symmetrically distributed around the center of the roadway, and the shape is approximately that of a "butterfly." There are no obvious zones of rock loosening in the floor and roof of the roadway

(2) With increased cross-sectional area, the range of the zone of rock loosening around the roadway gradually expands. Under different cross-sectional areas, 
TABLE 2: The range of the zone of rock loosening.

\begin{tabular}{lccc}
\hline $\begin{array}{l}\text { Cross-sectional } \\
\text { area } / \mathrm{m}^{2}\end{array}$ & $\begin{array}{c}\text { Apex angle of } \\
\text { roadway/m }\end{array}$ & $\begin{array}{c}\text { Roadsides/ } \\
\mathrm{m}\end{array}$ & $\begin{array}{c}\text { Bottom angle of } \\
\text { roadway/m }\end{array}$ \\
\hline 15 & 5.6 & 2.5 & 6.7 \\
20 & 6.3 & 3.0 & 6.8 \\
25 & 7.4 & 3.5 & 7.5 \\
30 & 7.8 & 4.0 & 7.5 \\
\hline
\end{tabular}

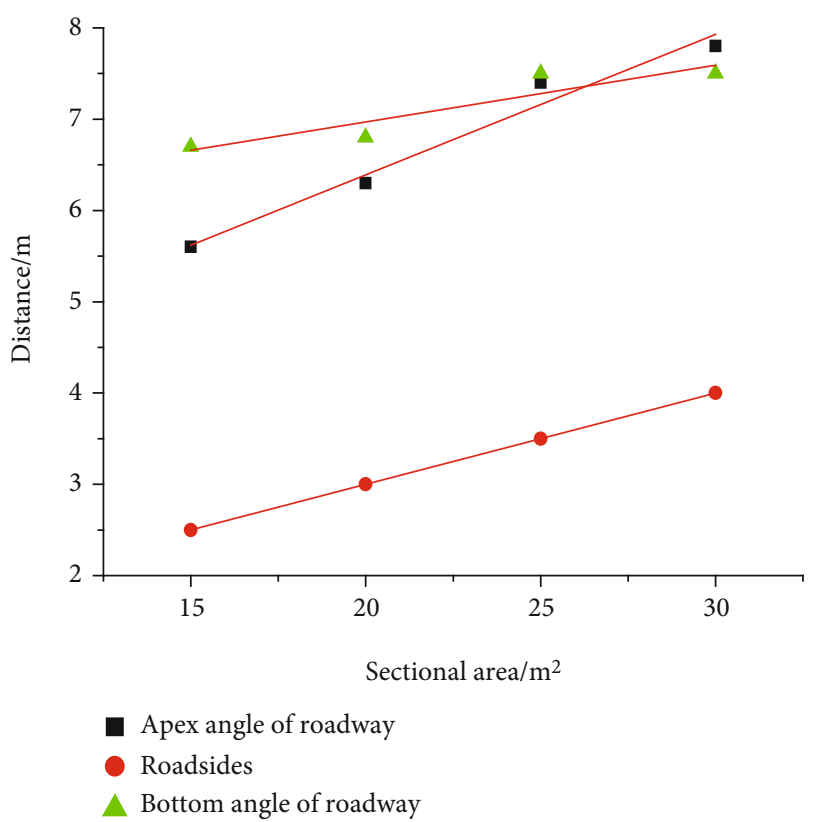

FIGURE 12: Distribution of the zone of rock loosening (failure area) at different positions as a function of change of cross-sectional area.

the range of the zone of rock loosening of the top and bottom corner is larger than that of the side of the roadway. The range of the zone of rock loosening at different positions with different cross-sectional areas is shown in Table 2

(3) The maximum stress is $8.61 \mathrm{MPa}, 8.87 \mathrm{MPa}$, $9.21 \mathrm{MPa}$, and $9.34 \mathrm{MPa}$, respectively, under the cross-sectional area of $15 \mathrm{~m}^{2}, 20 \mathrm{~m}^{2}, 25 \mathrm{~m}^{2}$, and $30 \mathrm{~m}^{2}$. The comparison shows that under the same conditions, as the cross-sectional area increases, the maximum stress gradually increases

Figure 12 shows the change curve of the zone of rock loosening at different positions as a function of the crosssectional area.

\section{Discussion}

Analyses of Table 2, Figures 10-12 lead to the following conclusions:

(1) The range of rock loose zone is the largest at the apex angle of roadway and the bottom angle of roadway, and it is roughly symmetrical. Therefore, it can be seen that as the cross-sectional area increases, the loose rock zone tends to develop on the "butterfly wings" (the largest at the apex angle of roadway and the bottom angle of roadway)

(2) The linear relationship between the range of the zone of rock loosening and cross-sectional area for the side of the road is $y=1+0.1 x$, and the correlation coefficient is 0.99 . For the top angle of the roadway, the linear relationship between the range of the zone of rock loosening and cross-sectional area is $y=$ $3.31+0.154 x$, and the correlation coefficient is 0.95 . Therefore, with increased cross-sectional area, the zone of rock loosening of the top angle and the side of the roadway increased

(3) With respect to the bottom corner of the road, the range of the zone of rock loosening did not change significantly with increased cross-sectional area. This was because the lithology of rock layer 1 is a finegrained sandstone, and its rock strength exceeds that of other rock layers. Consequently, fractures cannot continue to extend to large depths; they only continue to develop along the stratum until it is in equilibrium

\section{Conclusions}

We conducted the acoustic field tests to study the evolution law of the zone of rock loosening around the roadway under different cross-sectional areas. In addition, the rock roadway with different section area was used to perform numerical simulations. The simulation results under four different section areas matched the field tests results well, and the relationship between different positions and cross-sectional areas around the roadway is analyzed. Our conclusions are as follows:

(1) In order to measure the range of rock roadway loose circle, the acoustic method is used to test the surrounding rock crack detector CT-2 in the field. According to the changing law of wave velocity, the range of loosening zone can be determined. Among them, the rock loose zone of 1302 North floor mining roadway is in the range of $2.3-2.4 \mathrm{~m}$ on the side of the roadway, and in the central auxiliary transportation roadway, the rock loose zone is in the range of $2.7-2.9 \mathrm{~m}$ on the side of the roadway

(2) The loose rock area around the roadway is symmetrically distributed around the center of the roadway, and its shape is similar to the "butterfly" shape, and the loose rock zone tends to develop on the "butterfly wings." The range of the zone of rock loosening surrounding the roadway increased with increased cross-sectional area. For the side of the roadway, the linear relationship between the range of the zone of rock loosening and cross-sectional area was $y=a$ $+B X$ ( $a, B$ are coefficients), and the correlation coefficient was 0.99 . For the roadway top angle, the linear 
relationship between the range of the zone of rock loosening and cross-sectional area was $y=C+D X$ ( $C, D$ are coefficients), and the correlation coefficient was 0.95

(3) Through the study of the influence of different crosssection area on the range of surrounding rock loose area, the basis for determining the effective sealing distance of the borehole is provided. Through numerical simulation, the results show that: with the increase of cross-sectional area, the range of rock loose zone increases linearly with the increase of cross-sectional area. Therefore, in order to ensure the effectiveness of the sealing effect, it is necessary to change the sealing distance according to the size of the roadway section area, so as to achieve the distance outside the loose area

\section{Data Availability}

The data that support the findings of this study are tested by authors. It is provided in the supplementary material.

\section{Conflicts of Interest}

The authors declare that they have no conflicts of interest.

\section{Acknowledgments}

The authors want to thank the anonymous reviewers for their valuable suggestions. The authors also express their appreciation of the funding provided by the National Natural Science Foundation of China (No.51874122, No.51704100), Key R \& D and Extension Projects of Henan Province (202102310223,202102310545), Program for innovative research team of Henan Polytechnic University (T2019-4), the Fundamental Research Funds for the Universities of Henan Province (NSFRF180426), Program for Innovative Research Team of Henan Polytechnic University, and the Key Research Projects of Henan Higher Education Institutions (19B440004).

\section{Supplementary Materials}

Additional supporting information of tested data is provided in this section. All the data is tested in filed by authors. Supplementary material I: borehole data of 1302 North bottom extraction roadway (Figure 7). Supplementary material II: drilling data of central auxiliary transportation lane (Figure 8). (Supplementary Materials)

\section{References}

[1] M. He, H. Xie, S. Peng, and Y. Jiang, "Study on rock mechanics in deep mining engineering," Yanshilixue Yu GongchengXuebao/Chinese Journal of Rock Mechanics and Engineering, vol. 24, no. 16, pp. 2803-2813, 2005.

[2] Z. Zhang, C. Tang, Q. Yu, and D. Duan, "Numerical simulation on influence coefficient of lateral pressure on broken zone of circular aperture," Rock and Soil Mechanics, vol. 30, no. 2, pp. 413-418, 2009.

[3] S. Hu, F. Zhou, C. Zhao, and A. Xu, "Distribution characteristics of fracture field around gas drainage borehole in underground coal Mine," Disaster Advances, vol. 5, no. 4, pp. 1050-1054, 2012.

[4] Y. Sun, G. Li, J. Zhang, and D. Qian, "Experimental and numerical investigation on a novel support system for controlling roadway deformation in underground coal mines," Energy Science \& Engineering, vol. 8, no. 2, pp. 490-500, 2020.

[5] H. Xie, M. Gao, R. Zhang, G. Peng, W. Wang, and A. Li, "Study on the mechanical properties and mechanical response of coal mining at $1000 \mathrm{~m}$ or deeper," Rock Mechanics and Rock Engineering, vol. 52, no. 5, pp. 1475-1490, 2019.

[6] H. Xie, X. Zhao, J. Liu, R. Zhang, and D. Xue, "Influence of different mining layouts on the mechanical properties of coal," International Journal of Mining Science and Technology, vol. 22, no. 6, pp. 749-755, 2012.

[7] J. Hu, H. Wen, Q. Xie, B. Li, and Q. Mo, "Effects of seepage and weak interlayer on the failure modes of surrounding rock: model tests and numerical analysis," Royal Society Open Science, vol. 6, no. 9, 2019.

[8] F. Huang, H. Zhu, Q. Xu, Y. Cai, and X. Zhuang, "The effect of weak interlayer on the failure pattern of rock mass around tunnel - scaled model tests and numerical analysis," Tunnelling and Underground Space Technology, vol. 35, pp. 207-218, 2013.

[9] M. R. Zareifard and A. Fahimifar, "Analytical solutions for the stresses and deformations of deep tunnels in an elastic-brittleplastic rock mass considering the damaged zone," Tunneling \& Underground Space Technology, vol. 58, pp. 186-196, 2016.

[10] J. Chen, H. He, and Y. Zhang, "Dynamic and static analysis of mechanism of loosen zone in surrounding rock of tunnels," Chinese Journal of Geotechnical Engineering, vol. 33, no. 12, pp. 1964-1968, 2011.

[11] S. K. Sharan, "Analytical solutions for stresses and displacements around a circular opening in a generalized HoekBrown rock," International Journal of Rock Mechanics \& Mining Sciences, vol. 45, no. 1, pp. 78-85, 2008.

[12] S. K. Sharan, "Exact and approximate solutions for displacements around circular openings in elastic-brittle-plastic Hoek-Brown rock," International Journal of Rock Mechanics \& Mining Sciences, vol. 42, no. 4, pp. 542-549, 2005.

[13] P. Li, F. Wang, L. Fan, H. Wang, and G. Ma, "Analytical scrutiny of loosening pressure on deep twin-tunnels in rock formations," Tunnelling and Underground Space Technology, vol. 83, pp. 373-380, 2019.

[14] M. He, "Physical modeling of an underground roadway excavation in geologically $45^{\circ}$ inclined rock using infrared thermography," Engineering Geology, vol. 121, no. 3-4, pp. 165176, 2011

[15] Z. Xie, N. Zhang, X. Feng, D. Liang, Q. Wei, and M. Weng, "Investigation on the evolution and control of surrounding rock fracture under different supporting conditions in deep roadway during excavation period," International Journal of Rock Mechanics \& Mining Sciences, vol. 123, p. 104122, 2019.

[16] E. Cardarelli, C. Marrone, and L. Orlando, "Evaluation of tunnel stability using integrated geophysical methods," Journal of Applied Geophysics, vol. 52, no. 2, pp. 93-102, 2005.

[17] H. Xia, Y. Xu, and Y. Zhang, "Numerical simulation and experimental analysis of roadway surrounding rock loose 
circle under blasting vibration," in IEEE Computer Society, pp. 850-854, Qindao, Shandong, China, 2013.

[18] F. Wang, Z. Liu, and C. An, "Sonic wave testing technique for surrounding rock loose circle," in IEEE Computer Society, pp. 1720-1722, Qindao, Shandong, China, 2011.

[19] X. Liu, Y. Han, D. Li et al., "Anti-pull mechanisms and weak interlayer parameter sensitivity analysis of tunnel-type anchorages in soft rock with underlying weak interlayers," Engineering Geology, vol. 253, pp. 123-136, 2019.

[20] B. Shen, "Coal mine roadway stability in soft rock: a case study," Rock Mechanics and Rock Engineering, vol. 47, no. 6, pp. 2225-2238, 2014.

[21] W. Zhang, Z. He, D. Zhang, D. Qi, and W. Zhang, "Surrounding rock deformation control of asymmetrical roadway in deep three-soft coal seam: a case study," Journal of Geophysics and Engineering, vol. 15, no. 5, pp. 1917-1928, 2018.

[22] J. Yu, W. Yao, K. Duan, X. Liu, and Y. Zhu, "Experimental study and discrete element method modeling of compression and permeability behaviors of weakly anisotropic sandstones," International Journal of Rock Mechanics and Mining Sciences, vol. 134, p. 104437, 2020.

[23] J. Yu, G. Liu, Y. Cai, J. Zhou, and B. Tu, “Time-dependent deformation mechanism for swelling soft-rock tunnels in coal mines and its mathematical deduction," International Journal of Geomechanics, vol. 20, no. 3, 2020.

[24] H. Wang, D. Zhang, D. Deng, Y. Jiang, and Y. Liu, "Stress distribution characteristics of roadway surrounding rock damaged zone under non-hydrostatic pressure," Journal of China Coal Society, vol. 45, no. 11, pp. 3717-3725, 2020.

[25] H. Zhao, H. Cheng, L. Wang, Y. Liu, D. Ji, and Y. Zhang, "Distribution characteristics of deviatoric stress field and failure law of roadway surrounding rock under non-hydrostatic pressure," Journal of China Coal Society, vol. 46, no. 2, pp. 370-381, 2021.

[26] F. Hao, L. Sun, and M. Liu, "Study of shortest sealing depth with considering plastic softening and dilatancy," Journal of China University of Mining and Technology, vol. 43, no. 5, pp. 789-793, 2014.

[27] D. Li, C. Hou, and J. Bai, "Control mechanism and application of doubly supported roadways with large rigidity and high strength," Chinese Journal of Geotechnical Engineering, vol. 30, no. 7, pp. 1072-1078, 2008.

[28] K. Bian and M. Xiao, "Analytical solutions of circular tunnel under two-dimension unequal pressure considering dilatancy and softening," Chinese Journal of Rock Mechanics \& Engineering, vol. 30, no. S2, pp. 3831-3838, 2011.

[29] Y. Ju, Y. Wang, C. Su, D. Zhang, and Z. Ren, "Numerical analysis of the dynamic evolution of mining-induced stresses and fractures in multilayered rock strata using continuum-based discrete element methods," International Journal of Rock Mechanics and Mining Sciences, vol. 113, pp. 191-210, 2019.

[30] Y. S. Wang, Z. Q. Wu, and M. H. Li, The Field Ultrasonic Test of the Disturbance of Surrounding Rock by the TBM Construction, Trans Tech Publications: Hangzhou, China, 2012, Hangzhou, China, 2012.

[31] P. Cui, B. Yao, Y. Liu, J. Wei, and H. Li, “A new width measurement method of the stress relief zone on roadway surrounding rocks," Geofluids, vol. 10, 2019.

[32] M. Haseli, M. Layeghi, and H. Z. Hosseinabadi, "Evaluation of modulus of elasticity of date palm sandwich panels using ultra- sonic wave velocity and experimental models," Measurement, vol. 149, p. 107016, 2020.

[33] Y. Sun, S. Lu, and C. Zhou, "Development of the ultrasonic measurement technique and its application in the observation of rock mass stability," Geotechnical \& Geological Engineering, vol. 11, no. 4, pp. 273-284, 1993.

[34] F. Cui, X. P. Lai, and J. T. Cao, Exploration Technology of Sound Wave and Electromagnetic Wave United Optical Imagining Verification for Evaluating Stability of Mining Roadway in Steeply Dipping Coal Seams, Shanghai, China, Taylor and Francis-Balkema: Shanghai, China, 2013.

[35] Z. Zhao, N. Ma, X. Guo, X. Zhao, Y. Xia, and Z. Ma, "Mechanism conjecture of butterfly rock burst in coal seam roadway," Journal of China Coal Society, vol. 41, no. 11, pp. 2689-2697, 2016. 